\title{
A risk assessment tool for the ship recycling industry
}

\author{
R. E. Kurt ${ }^{1}$, S. A. McKenna ${ }^{1}$, S. A. Gunbeyaz ${ }^{1}$, K. G. Rogge ${ }^{2}$, \\ O. Turan ${ }^{1} \&$ I. H. Helvacioğlu \\ ${ }^{1}$ Department of Naval Architecture, Ocean and Marine Engineering, \\ University of Strathclyde, UK \\ ${ }^{2}$ AratraZeneca, Sweden \\ ${ }^{3}$ Faculty of Naval Architecture and Ocean Engineering, \\ Istanbul Technical University, Turkey
}

\begin{abstract}
Ship recycling operations expose workers to a wide range of hazards that can cause a large number of incidents and accidents resulting in ill health, injuries and even death. In order to facilitate effective risk reduction within ship recycling yards, there is a need to develop an appropriate risk assessment method that is supportive and simple to use. In addition, the utilised method should involve end-user participation which is very important in assisting the realisation and acceptance of required health and safety measures. In this paper, a new bespoke risk assessment methodology for ship recycling, 'The Three Step Risk Assessment Method for Ship Recycling' (Three Step Method) will be presented which fulfils the criteria's mentioned above. This paper will document the Three Step Method's development and explain its various steps of implementation before introducing a case study and feedback of a practical application of the method. Finally, the conclusions that the Three Step Method provides a proven useful dialogue in the identification, assessment and mitigation of hazards and that the method can be easily implemented in the ship repair industry will be made.
\end{abstract}

Keywords: risk, hazard, risk assessment, ship recycling, ship breaking, ship dismantling, job task analysis. 


\section{Introduction}

Ship recycling is a dangerous industry in which some workers' health and safety is being compromised on a daily basis. For example, YPSA [1] reports that between 2005 and 2011, more than ninety workers lost their lives in the ship recycling yards in Bangladesh. Likewise, in India, according to the report by GMB [2] 348 workers died between 1991 and 2007. Finally, in Turkey, 36 workers lost their lives between 1985 and 2007 according to the reports by CSGB $[3,4]$. Reports and feedback from all main ship recycling locations in the world are continually portraying a working environment which is dangerous and ignoring basic hazard identification and risk management principles, which is directly leading to incidents which cause injury, ill health and death.

Bohle and Quinlan [5] argue that hazard identification and risk management in any industry are important factors in achieving safe operations. ILO [6] states that with ship recycling being a labour intensive and heavy industry it has been noted by many industry experts and academics that having a risk management approach is crucial in achieving improved safety performance. Therefore, in order to address these shortcomings a new bespoke risk assessment methodology for ship recycling, 'Three Step Risk Assessment Method for Ship Recycling' (Three Step Method) has been developed and will be subsequently presented within this paper.

In this paper, the principles behind the Three Step Method will be introduced, its methodology explained, and a case study of a ship recycling job task will be presented.

\section{Background}

The Three Step Method was developed as part of an European Union funded project called 'Dismantling of Vessels with enhanced Safety and Technology' (DIVEST [7]). In the DIVEST project part of its objective was to observe and analyse various ship recycling practices in order to identify areas of improvement. Within DIVEST, one of the key areas for improvement noted by researchers was the lack of planning and awareness amongst all levels of ship recycling employees. Therefore, the foundation of the idea of creating a structured and guided way of approaching job tasks while incorporating hazard identification and risk management was formed.

\subsection{Planning and preparation}

With new regulations being imposed on the ship recycling industry from bodies such as the International Maritime Organisation's (IMO) Hong Kong Convention [8] and the EU's Ship Recycling Regulation [9], the burden of additional planning and administration work of ship recycling yards has increased. It was observed by the researchers of this paper that this extra administration work was not being fully adapted into the working polices of the yard and was simply being viewed and executed as a paperwork exercise. Documents such as the 
'Ship Recycling Plan', 'Ship Recycling Facility Plan' and the 'Inventory of Hazardous Materials', required by the aforementioned regulations, were not being adequately utilised as a tool for better planning and increasing worker safety.

Therefore, it was decided that the proposed Three Step Method would include a dedicated planning and preparation phase in order to explain step by step the required information required and to give context and relevance to the ship recycling employee. This will contribute to ensuring the important documents and information provided will be utilised in a manner which will make a difference.

\subsection{Hazard identification}

The next key aspect to address in this new approach in relation to ship recycling was hazard identification. In ship recycling, workers are faced with numerous hazards. These can range from obvious construction site related hazards such as falling from heights and falling objects to hidden hazards such as exposure to asbestos fibres. From observations and feedback from those responsible for health and safety it became clear that due to the sheer number of potential hazards in ship recycling operations it was hard to systematically consider and act to address them without a structured approach. In addition, there was also the issue of those responsible for health and safety not being aware of some of the less obvious hazards. Therefore, the requirement for an inclusive guide list of potential ship recycling hazards which ship recycling employees could use as a reference was required.

Within ship recycling, many efforts by various organisations have been made to document ship recycling hazards in an all-encompassing list (ILO [6], OSHA [10]). The International Labour Organisation in particular had suggested a comprehensive list of hazards which was selected for utilisation in the Three Step Method ILO [6]. In addition, to add extra support. by providing context to the hazards to the risk assessment team, additional causal risk factors were added from further sources including; Job Safety Analysis (Harms-Ringdahl [11]), Safety and health in ship breaking, Guidelines for Asian countries and Turkey, ILO [6], Occupational safety and health manual, for the ship recycling workers in Bangladesh, ILO, Ministry of Labour and Employment Bangladesh and UNDF within the SAFEREC project 2003-2007 [12].

In addition, to further support the risk assessment team in identifying hazardous situations it was agreed to create examples of hazardous job tasks. This was compiled from various observations of ship recycling activities and was categorised into the specific zones within a ship recycling facility.

By providing a list of hazards, risk factors and examples of hazardous job tasks to the risk assessment team it allows for all potential hazards to be considered in a systematic way. It also provides potential education to the risk assessment team in terms of considering hazards which they might not have thought of before. 


\subsection{Risk assessment}

There are multiple risk assessment methodologies available but within the context of ship recycling it was important to choose or create one which would address the unique needs of the industry. Particular needs included the requirement to assess the hazards accurately in a manner which was simple, easy to follow and which included all members of staff involved. In many existing methods it was found that there was a gap in the identification of hazards in relation to a job task which adequately supports the user in a step-by-step fashion.

Therefore, an approach was suggested which would utilise components of 'Job Safety Analysis' and 'Energy Analysis' (Harms-Ringdahl [11]). Particular components included the 'checklist' approach in which the user systemically considers all potential hazards applicable to the chosen job task, and prescreening which allows for the most critical of hazardous to be further assessed in a deeper risk assessment stage and for mitigating actions to be suggested.

By tailoring the risk assessment and mitigation suggestion phase of the Three Step Method, it allows for the risk assessment team involved to assess hazardous in a structured but simple manner.

In summary, the rationale behind the Three Step Method is to provide a structured approach to risk assessment in ship recycling yards tailored to the unique needs of the industry. In the next section the methodology will be explained.

\section{Three Step Method}

The overall structure of the Three Step Method is demonstrated in Figure 1.

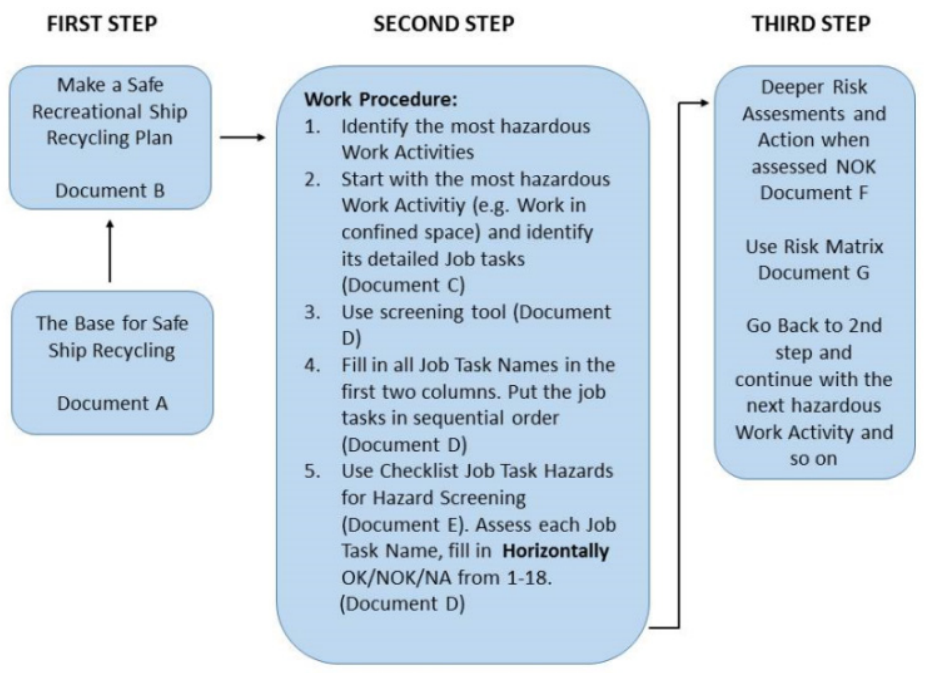

Figure 1: The Three Step Method. 


\subsection{First step}

The first step of the Three Step Method ensures all the basic requirements by national and international bodies for Ship Recycling activities are fulfilled. This step is the foundation of every ship recycling yard's operation and is separated into two sections; A Base for Ship Recycling and A Safe Ship Recycling Plan (ship specific).

\subsubsection{A base for ship recycling: (Document $A$ )}

The base for ship recycling states all the required documentation, permissions required and polices of the ship recycling facility. Examples include; ship recycling facility plan, standard procedures, emergency procedures, local waste management regulations, etc.

\subsubsection{A safe ship recycling plan (ship specific): (Document B)}

For every ship accepted by a yard to be recycled, the ship recycling facility should develop a ship recycling plan. Each ship is unique in terms of hazards on board and it is important to carefully plan each stage of the dismantling and recycling process. In Step 1 of the Three Step Method a check list is provided to ensure the ship recycling facility has satisfied all requirements. The check list includes tasks such as the obtaining and utilising the IHM, creating a decontamination plan, emergency preparedness plans, securing and shutting down the ship, etc.

\subsection{Second step}

At the very beginning of the second step the health and safety manger (H\&S manager) will form a risk assessment team in order to assist. This team should ideally include all personal involved in the job task and, if available, additional experts in occupational health and safety, ship recycling, etc.

The scope of the risk assessment will be defined by the H\&S manager at the start of the meeting i.e. is the focus only one specific job task or the whole dismantling process of a vessel.

After, the next stage of the process is the identification of hazardous job tasks associated with ship recycling. Through utilising the created "Examples of Hazardous Job Tasks" (Document C) (Table 1) the group will focus on the job tasks in a step wise fashion.

After selecting the first hazardous job task, the group inputs this task into the screening tool (Document D). The screening tool allows for the group to perform a pre assessment of all potential hazards which are shown in the Job tasks "Hazards for Hazards Screening" (Document E). The group simply takes each job task and works systematically through the hazard list asking the question if this hazard in any way exists in the chosen job task. In the opinion of the group, if the hazard does not exist then it is deemed to be 'Okay', if it does exist it is marked 'Not Okay' and is automatically carried forward for deeper risk assessment in the third step. 
Table 1: Examples of hazardous job tasks [13].

\begin{tabular}{ll}
\hline A: Primary block breaking area & B: Secondary block breaking area \\
\hline $\begin{array}{l}\text { Entry into confined, enclosed, and other } \\
\text { dangerous atmosphere }\end{array}$ & $\begin{array}{l}\text { Sorting of components } \\
\text { Paint removal }\end{array}$ \\
& $\begin{array}{l}\text { Further cutting into suitable size for } \\
\text { further transportation }\end{array}$ \\
Metal cutting and disposal & $\begin{array}{l}\text { Definitive sorting of materials and } \\
\text { equipment }\end{array}$ \\
Bilge and ballast removal & Finishing of materials for re-sale \\
Oil and fuel removal and tank cleaning & Overhauling of equipment \\
\hline
\end{tabular}

\subsection{Third step}

In the third step, the hazards for the job task judged by the group to be 'Not Okay' are carried forward to the 'Deeper Risk Assessment Sheet' (Document F). In this section more information about the hazard is required to be discussed and then documented by the group. The group inputs further information in relation to casual risk factors, location, potential effects and then calculates a risk level $(\mathrm{R})$ based on the severity $(\mathrm{S})$ and probability $(\mathrm{P})$ the group deems the hazard to have. The group is assisted in this task through the utilised of a predefined risk matrix in DIVEST [13] project (Table 2 and Figure 3).

For hazards which are rated 2 or above in the risk matrix hazard control/safety measures should be defined and re-assessed as before. Multiple measures and iterations of the risk assessment process may be required before an acceptable solution(s) is found. An action for implementation, responsibility and due date should be assigned during by the group during the risk assessment meeting. The process is then repeated for additional hazards and job tasks.

Table 2: Degree of probability, severity of consequences and rating.

\begin{tabular}{lclc}
\hline Degree of Probability & Rating & Severity of Consequences & Rating \\
\hline Very frequent, once a day & 5 & Death or several deaths & 5 \\
Frequent, once per week & 4 & Disability & 4 \\
Quite frequent, once per month & 3 & Longer reporting sick $>14 \mathrm{~d}$ & 3 \\
Quite unusual, once a year & 2 & Shorter reporting sick $<14 \mathrm{~d}$ & 2 \\
Unlikely, once per 10 years & 1 & Injury without reporting sick & 1 \\
Very unlikely, once per 100 years & 0 & Negligible or harmless injury & 0 \\
\hline
\end{tabular}




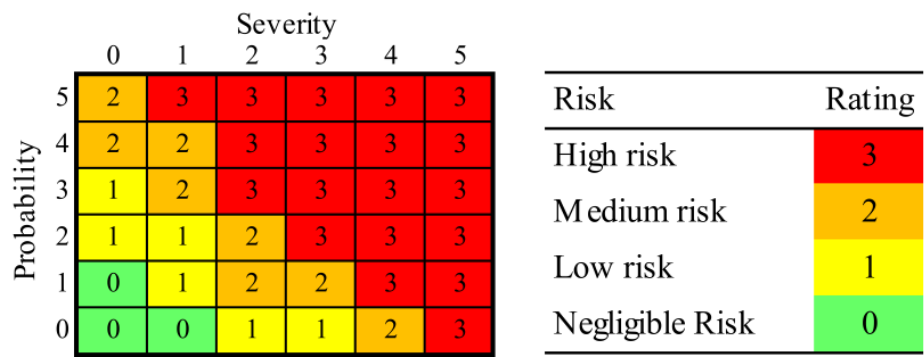

Figure 2: The risk matrix.

\subsection{Three Step risk assessment tool}

The Three Step Method has been subsequently developed into a software programme to allow for enhanced overall risk profile representation, user experience and documentation in DIVEST [13] (Figure 3).

\section{Case study}

In order to validate the Three Step Method as being applicable to the ship recycling industry and easy to use, a case study was conducted in a real ship recycling scenario.

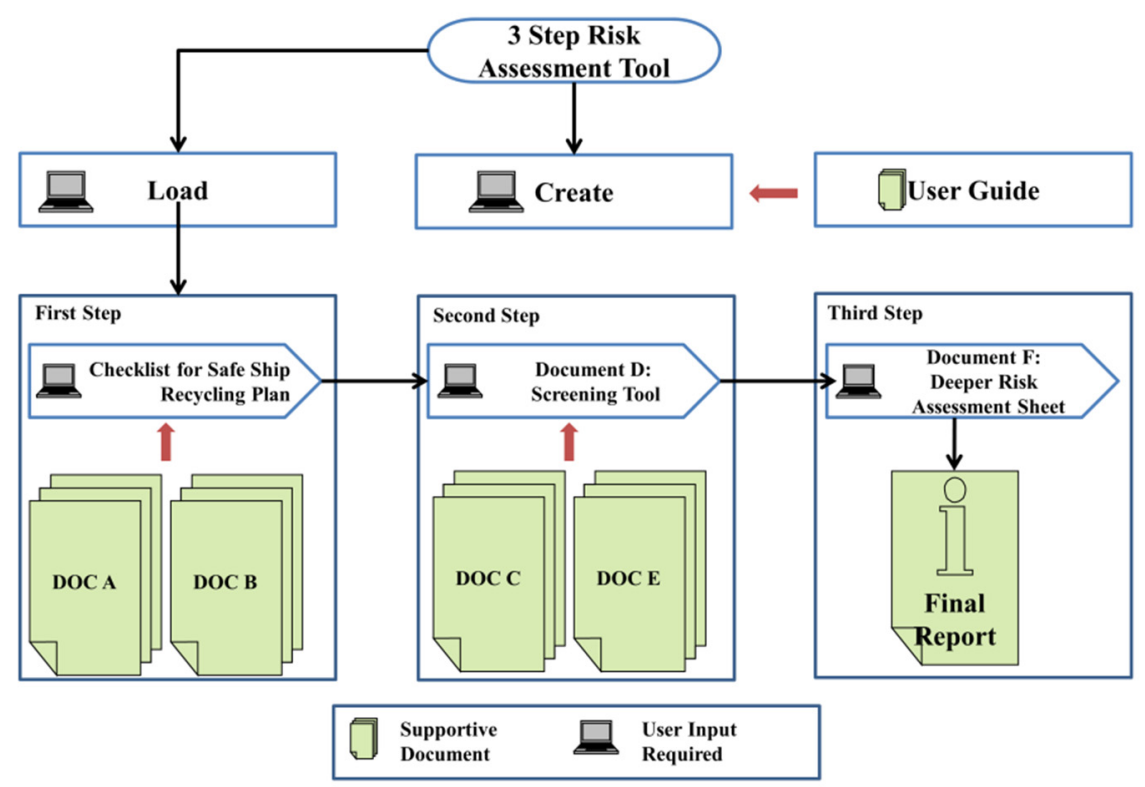

Figure 3: Algorithm of the Three Step tool. 
The case study involved following the overall objective of removing and cutting up a steel section from a ship. This process involved 4 job tasks:

- Job task 1: workers' access to the ship from the ground by a crane with a basket,

- Job task 2: On-board cutting of ships structure in an L shape panel section using oxy-lpg cutting,

- Job task 3: lifting of the cut steel structure with a crane to a truck and transport of the steel to the secondary cutting zone and,

- Job task 4: cutting up of steel structure to smaller pieces in the secondary cutting zone.

A team of experts and those familiar with ship recycling was formed to conduct the risk assessment. The team had access to detailed video footage of all job tasks mentioned above. The team comprised of:

- 2 ship recycling experts

- 1 researcher

- 3 ship building engineers

- 4 health, safety and environment experts.

The Three Step Method was followed, inputting all information into the tool. Hazards were successfully identified, assessed and mitigating actions suggested where applicable. An example of the deeper risk assessment stage for the secondary zone steel cutting (Job Task 4) can be found in Table 3.

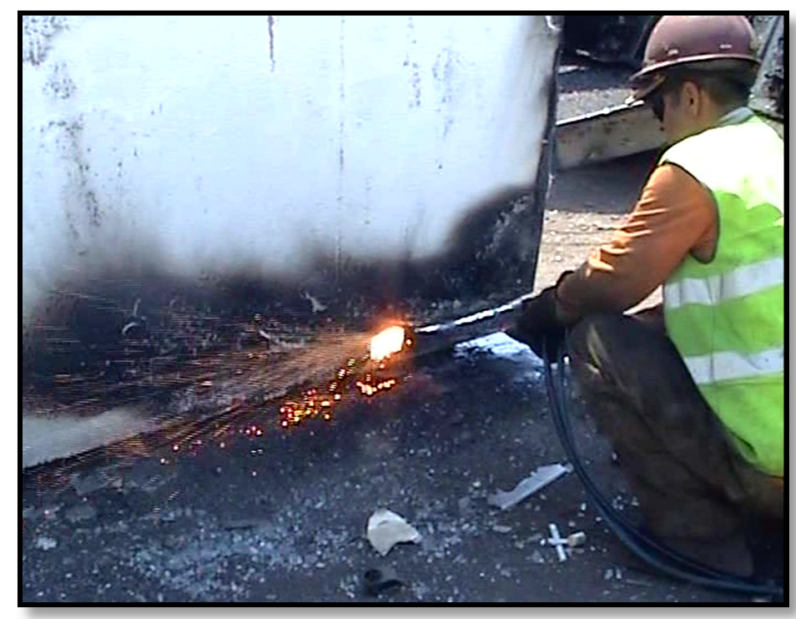

Figure 4: Worker cutting up a steel structure in the secondary cutting zone. 


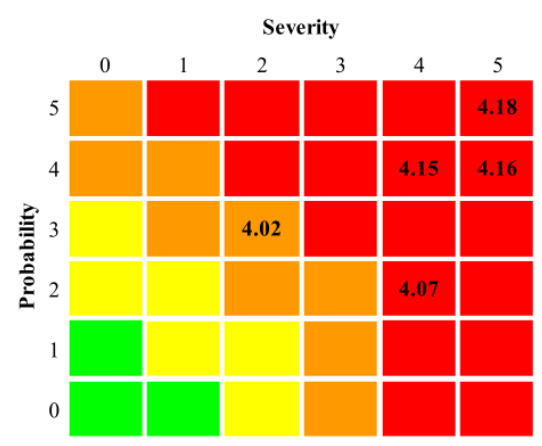

Before

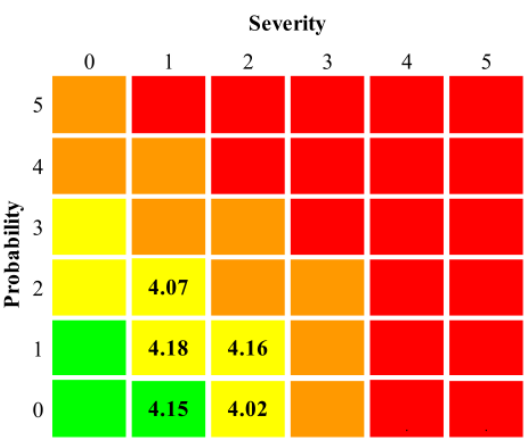

After

Figure 5: Risk matrix before and after the measures.

After the Three Step Method had been completed the risk assessment team was asked to offer feedback on the method. The feedback received was positive with minor points of suggested improvement. Overall, the case study demonstrated the Three Step Method was applicable to ship recycling and easy to use. Since this case study the method has been trialled with Indian, Turkish, British and Spanish ship recyclers who have all reported positive experiences. The following is a sample of some of the comments received during ship recycling training in Aliaga Turkey as a part of ShipDIGEST [15] project:

"The systematic process of checking the hazard list for every job task will ensure all potential hazards are considered and even educate ship recyclers of previously unknown hazards."

"The method is simple and structured enough even for those with limited experience of hazard identification and risk assessment."

\section{Conclusions}

Ship recycling facilities are being required to fulfil extra legislation and regulations which are currently being regarded as extra paperwork and an inconvenience. In addition, ship recycling workers worldwide continue to be placed in danger due to a lack of proper hazard identification and risk management.

The Three Step Method aims to address both of these issues by providing ship recycling facilities with the support and structure to meet their responsibilities in a productive and useful manner, in addition to lowering the exposure of workers to dangerous situations through easy and simple to use risk assessment.

The Three Step Method has been developed exclusively for the needs of the ship recycling industry and, as this paper has shown, has been well received by occupational health and safety experts and ship recyclers alike. 


\begin{tabular}{|c|c|c|c|c|}
\hline & $\simeq$ & - & - & 0 \\
\hline \multirow{2}{*}{ 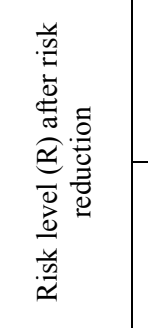 } & $a$ & 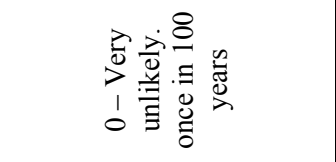 & 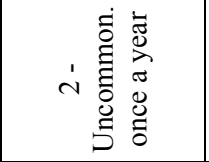 & 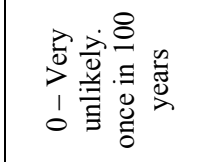 \\
\hline & $n$ & 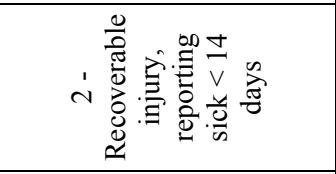 & 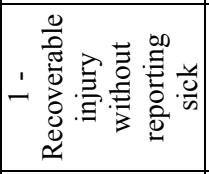 & 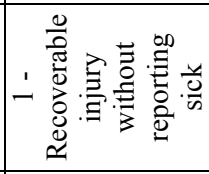 \\
\hline 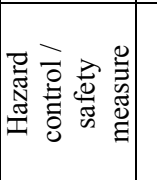 & & 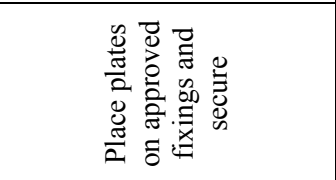 & 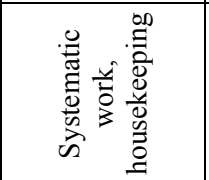 & 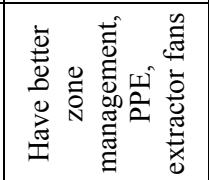 \\
\hline & $\simeq$ & $N$ & $m$ & $m$ \\
\hline \multirow{2}{*}{ 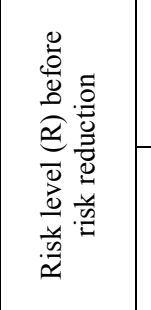 } & $a$ & 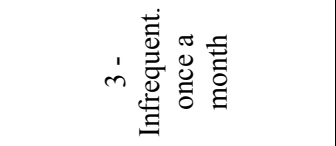 & 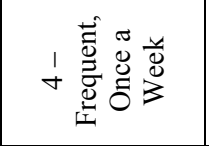 & 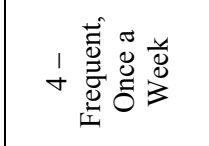 \\
\hline & $n$ & 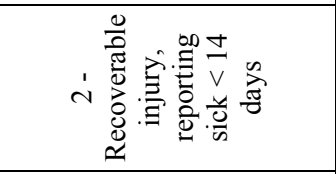 & 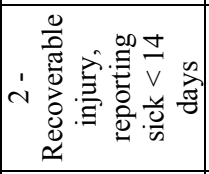 & 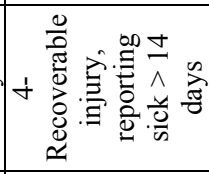 \\
\hline \multicolumn{2}{|l|}{ 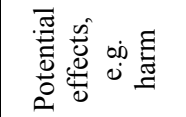 } & 莺 & 焉 & 占 E छ \\
\hline \multicolumn{2}{|l|}{ 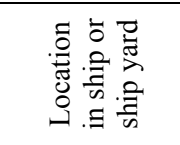 } & 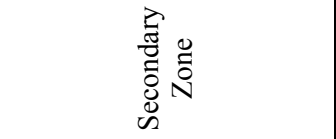 & 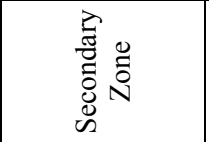 & 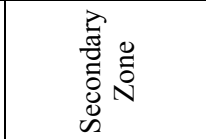 \\
\hline \multicolumn{2}{|l|}{ 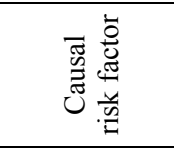 } & 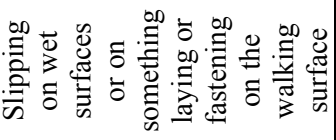 & 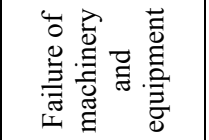 & 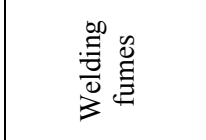 \\
\hline \multicolumn{2}{|l|}{ 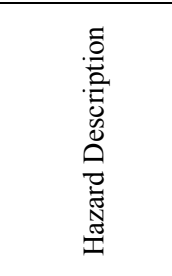 } & 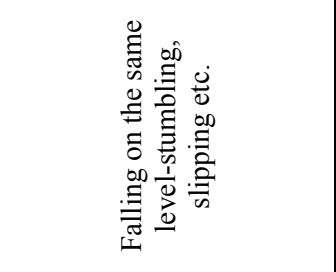 & 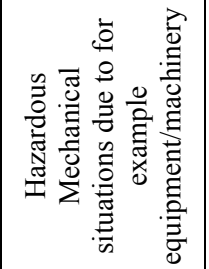 & 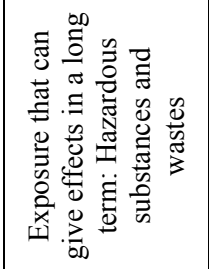 \\
\hline \multicolumn{2}{|l|}{ 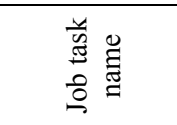 } & 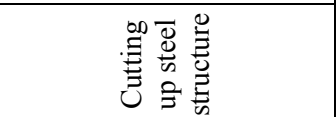 & 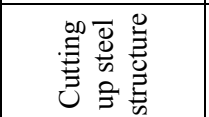 & 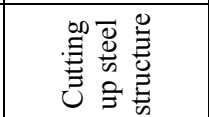 \\
\hline \multicolumn{2}{|l|}{$\stackrel{\circ}{\stackrel{y}{\sharp}}$} & $\underset{\stackrel{\sigma}{~}}{\stackrel{\sigma}{*}}$ & $\underset{\dot{\sigma}}{\hat{\sigma}}$ & $\stackrel{n}{\stackrel{\sigma}{\sigma}}$ \\
\hline
\end{tabular}




\begin{tabular}{|c|c|c|c|}
\hline & $\simeq$ & - & - \\
\hline \multirow{2}{*}{ 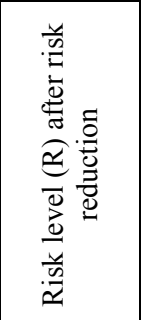 } & $a$ & 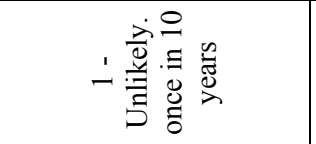 & 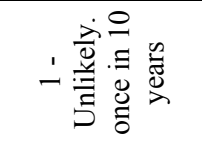 \\
\hline & $\infty$ & 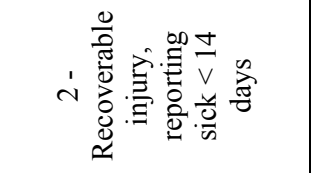 & 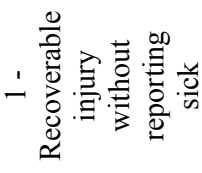 \\
\hline \multirow{2}{*}{ 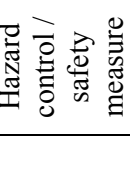 } & & 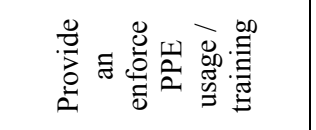 & 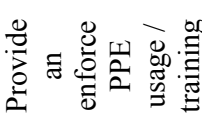 \\
\hline & $\simeq$ & & $m$ \\
\hline \multirow{3}{*}{ 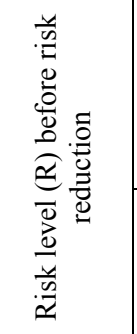 } & \multirow[b]{2}{*}{$\theta$} & & \\
\hline & & 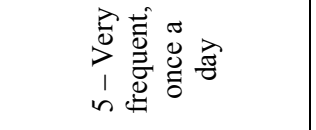 & 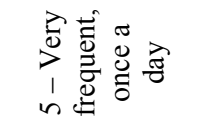 \\
\hline & $\infty$ & 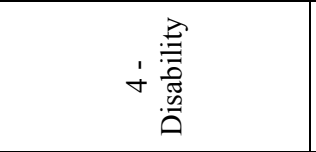 & 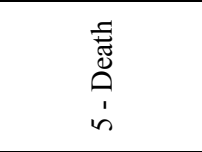 \\
\hline \multicolumn{2}{|c|}{ 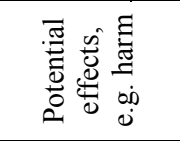 } & 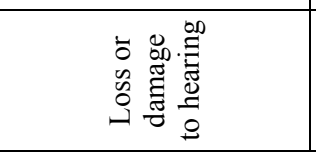 & 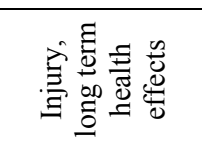 \\
\hline \multicolumn{2}{|l|}{ 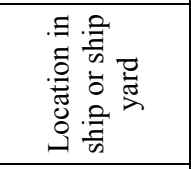 } & 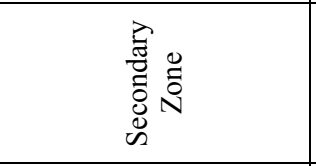 & 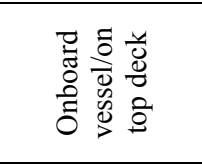 \\
\hline \multicolumn{2}{|l|}{ 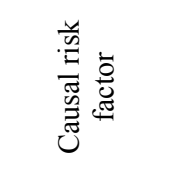 } & 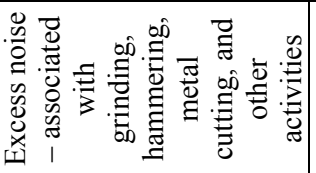 & 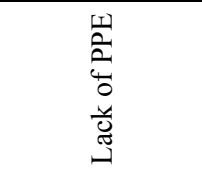 \\
\hline \multicolumn{2}{|l|}{ 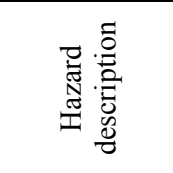 } & 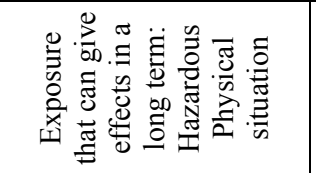 & 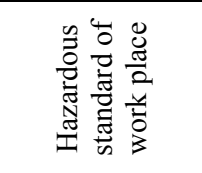 \\
\hline \multicolumn{2}{|l|}{ 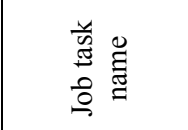 } & 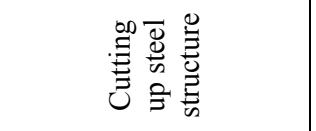 & 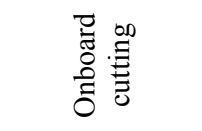 \\
\hline \multicolumn{2}{|l|}{ 응 } & $\begin{array}{l}0 \\
\dot{*}\end{array}$ & $\stackrel{\infty}{\underset{\sim}{*}}$ \\
\hline
\end{tabular}


The future plans for the Three Step Method are to further promote and encourage its use in ship recycling yards around the world and expand to include application in the dangerous ship repair industry as well.

\section{Acknowledgements}

The research presented in this paper has been supported by the EU funded FP7 DIVEST and Leonardo Da Vinci Programme funded Ship DIGEST Projects.

\section{References}

[1] (YPSA), Y.P.i.S.A. A list of dead workers from the year of 2005 to 2012 (September). 2012; Available from: http://www.shipbreakingbd.info /death trap.html.

[2] GMB, Gujarat Maritime Board. 2004.

[3] CSGB, Gemi sokumu yapilan isyerlerinde is sagligi ve guvenligi proje denetimi degerlendirme raporu. 2005, Calişma ve sosyal guvenlik bakanligi.

[4] CSGB, Gemi sokum isyerlerinde is sagligi ve guvenligi teftis projesi-2. 2007(Calisma ve sosyal guvenlik bakanligi).

[5] Bohle, P. and M. Quinlan, Managing occupational health and safety: $A$ multidisciplinary approach. 2000: Macmillan Education AU.

[6] ILO, Safety and health in shipbreaking: Guidelines for Asian countries and Turkey, I.L.O. Geneva, Editor. 2003: Bangkok.

[7] DIVEST, DIsmantling of Vessels with Enhanced Safety and Technology. 2009.

[8] IMO, The Hong Kong International Convention for the Safe and Environmentally Sound Recycling of Ships. 2009, International Maritime Organization.

[9] EU, The EU Ship Recycling Regulation. 2013.

[10] OSHA, U.S. Department of Labour, Safety and Health Administration.

[11] Harms-Ringdahl, L., Safety Analysis, Principles and Practice in Occupational Safety. 2001.

[12] SAFEREC, Ship Recycling in Bangladesh, Findings on the Baseline Survey of the Ship Recycling Yards, Safe and Environment Friendly Ship Recycling Project (SAFEREC). 2005, International Labour Organisation, Government of the People's Republic of Bangladesh, United Nations Development Programme.

[13] DIVEST, Report on Selected RA Method, Deliverable No: 3.3, 3.4, 3.5 and 3.7. 2009.

[14] ShipDIGEST, ShipDIGEST Project. 2013, EU Life Long Learning Programme.

[15] ShipDIGEST, ShipDIGEST Pilot and Validation. 2-5 July 2013: Aliaga, Izmir. 